must have been collected and the authors are to be complimented on the clear and readable way in which the results are presented.

Each chapter looks to a different stage in the procedure and ends with a summary of the main findings. Tables and figures are kept to a minimum and complex statistical tests are avoided. The book concludes with a discussion of the implications of the findings and recommendations are made on how procedures should be changed.

One of the most striking findings of the study is the general level of ignorance and confusion found among the police, psychiatrists and social workers regarding the purpose and legal requirements of section 136. A few examples of the misuse of the section will suffice: the police using section 136 when the person arrested was on private property instead of "a place to which the public have access"; patients being admitted under the section; and social workers either not being asked to interview the patient or refusing to come.

I have some criticisms of the study. Firstly, the way in which cases were referred to the researchers, which largely depended on officers responding to a previously circulated memorandum. Several police stations did not refer any cases during the one year study period. The authors concede that this may have led to a selection bias and the conclusions must be interpreted accordingly.

Secondly, statistical tests are not used to analyse the data. So a conclusion that $A$ happens more often than $B$ is made in the absence of probability values or confidence intervals. Thirdly, the authors do not seem to be aware of some of the recently published work on section 136 which has appeared in the psychiatric press. A final criticism regards the quality of the printing, which at times is very poor and gives one the sensation of having diplopia.

In conclusion, this is an important study and one which should be made compulsory reading for all professionals involved in the use of section 136. Finally, the Metropolitan Police must be congratulated on cooperating with MIND in allowing the study to take place at all.

\section{Senior Registrar}

JOHN DUNN

London SE5 8 AZ

\section{'The Taming of the Shrew'}

The British Psycho-Analytical Society will be holding a dialogue between the director and members of the cast of 'The Taming of the Shrew' at the Royal Shakespeare Theatre, Stratford-upon-Avon, and Gerald Wooster, psychoanalyst, following a matinee performance of the play on 4 July 1992. Further information and tickets: Ann Glynn, The Institute of Psycho-Analysis, 63 New Cavendish Street, London W1M 7RD.

\title{
Scientific debate
}

The British Association for Social Psychiatry (BASP) scientific debate 'Dealing with Childhood Sexual Abuse: Dawn Raid or Family Therapy' will be held on 30 June 1992 at London Bridge Hospital at 7.30 p.m. All are welcome and there is no charge.

If attending, please inform Professor A. H. Crisp, Chairman BASP, Department of Mental Health Sciences, St George's Hospital Medical School, London SW170RE (telephone 081672 9944, extension 55540). 